\title{
DE 1977 A 2020. LA DEROGACIÓN DEL ART. 52.D) DE LA LEY DEL ESTATUTO DE LOS TRABAJADORES («DESPIDO POR ABSENTISMO») *
}

\author{
Eduardo ROJO TORRECILLA \\ Catedrático de Derecho del Trabajo y de la Seguridad Social \\ Departamento de Derecho Público y Ciencias Histórico-Jurídicas \\ Facultad de Derecho de la Universidad Autónoma de Barcelona \\ eduardo.rojo@uab.cat
}

\section{INTRODUCCIÓN}

El 30 de diciembre de 2019 se firmaba por los secretarios generales del PSOE y Unidas Podemos el documento «Coalición progresista. Un nuevo acuerdo para España», el pacto de legislatura que abrió el camino a la formación de un gobierno de coalición entre ambas fuerzas políticas tras el nombramiento de Pedro Sánchez como presidente del Gobierno.

En dicho texto se diferenciaba entre las medidas de más largo alcance tendentes a una reforma en profundidad de la Ley del Estatuto de los trabajadores (LET) y la elaboración de «un nuevo Estatuto de los Trabajadores del siglo XXI», con indicación de las líneas marco que debían guiarla, con la tajante afirmación de que la reforma laboral, que se concretaba que era la de 2012, sería derogada y se recuperarían los derechos laborales «arrebatados» por aquella, acordando que tal recuperación sería efectuada «con carácter urgente» para algunos de sus contenidos.

Entre las medidas urgentes se hacía expresa mención de la derogación del art. 52.d), el coloquialmente llamado «despido por absentismo», es decir, que las bajas aun jutificadas por contingencias comunes y con los requisitos regulados en dicho precepto puedan ser causa de extinción del contrato. Se daría de esta forma «respuesta» normativa a la Sentencia del Tribunal Constitucional (STC) núm. 118/2019, de 26 de octubre, que

* Tras su tramitación parlamentaria, el RDL 4/2020 se convirtió, sin modificaciones, en la Ley $1 / 2020$, de 15 de julio. 
desestimó la cuestión de inconstitucionalidad interpuesta por el Juzgado de lo Social núm. 26 de Barcelona ${ }^{1}$.

Conviene recordar, a los efectos de mi exposición posterior, que esta causa de extinción fue regulada hace ya muchos años, en concreto en el Real Decreto-ley (RDL) 17/1977, de 4 de marzo, sobre relaciones de trabajo, en cuyo art. 39.1.d) se contemplaba en los siguientes términos: «Las faltas, aun jutificadas, de asistencia al trabajo, cuando fueren intermitentes, superen en un año el treinta por ciento de las jornadas y no respondan a accidente o enfermedad que produzcan incapacidad continuada de larga duración». Dicho precepto fue derogado por la disposición final tercera, apartado quince, del texto original de la LET, la Ley 8/1980, de 10 de marzo.

Tal como han explicado María Emilia Casas y Miguel Rodríguez-Piñero: «El fundamento jurídico de esta causa de despido objetivo reposaba así, en última instancia, en la exoneración al empleador de las consecuencias para el perjudicado de la ejecución intermitente de la prestación de trabajo por ausencias justificadas no imputables a la persona trabajadora, trasladando a ésta el riesgo de esas inasistencias justificadas al permitir su despido aunque no hubiera existido un incumplimiento contractual grave y culpable. El despido reaccionaba frente a unas inasistencias intermitentes al trabajo que suponían el no cumplimiento de la prestación laboral con la consecuencia de que el empleador no obtuviera la utilidad esperada de una prestación duradera y continuada del trabajador y la consiguiente frustración del objeto perseguido por el contrato» ${ }^{2}$.

${ }^{1}$ Vid. un análisis crítico de dicha sentencia a cargo de J. L. Monero y S. GuinDOS, «Sobre la constitucionalidad del despido objetivo fundamentado en la causa $d$ ) del art. 52 del Estatuto de los Trabajadores», Revista de Jurisprudencia Laboral, núm. 3 (2019), disponible en https://www.boe.es/publicaciones/anuarios_derecho/articulo.php? id=ANUL-2019-00000000646 (consultado el 20 de abril). Para los autores, «la letra d) del art. 52 del ET posee, criticablemente, un carácter cuasidisciplinario o presuntamente disciplinario, puesto que, del tenor literal de la misma se puede inferir la sospecha o presunción de un comportamiento irregular o de fraude por parte de las personas trabajadoras. Lo cual contrasta, paradójicamente, con la lógica jurídica interna general del propio art. 52 del ET, que está basada en la existencia de circunstancias objetivas no constitutivas en ningún caso de incumplimientos contractuales del trabajador afectado, por contraposición a la enteramente diversa racionalidad interna del art. 54 ET.

Por lo que, paradójicamente, nos encontramos ante una causa de despido objetivo no objetiva, sino subjetiva (pues subyace un juicio de reproche que sería más propio de una presunción de culpabilidad), puesto que se castiga a los trabajadores que enferman — principal leitmotiv de esta causa extintiva de la relación laboral—, aun cuando sus bajas laborales son justificadas».

${ }^{2}$ M. ${ }^{a}$ E. CASAS y M. Rodríguez-PiÑERo, «El Estatuto de los Trabajadores y la derogación de su art. 52.d)», Derecho de las Relaciones Laborales, núm. 3 (2020). Los autores, que realizan un amplio repaso de las modificaciones normativas operadas desde la prime- 
La LET mantuvo la causa de extinción, con algunas modificaciones, en el art. 52.d) en estos términos: «Por faltas de asistencia al trabajo, aun jutificadas, pero intermitentes, que alcancen el veinte por ciento de las jornadas hábiles en dos meses consecutivos, o el veinticinco por ciento en cuatro meses discontinuos dentro de un periodo de doce meses, siempre que el índice de absentismo del total de la plantilla del centro de trabajo supere el cinco por ciento en los mismos periodos de tiempo. No se computarán como faltas de asistencia, a los efectos del párrafo anterior, las ausencias debidas a huelga legal por el tiempo de duración de la misma, el ejercicio de actividades de representación legal de los trabajadores, accidente de trabajo, maternidad, licencias y vacaciones, ni enfermedad o accidente no laboral, cuando la baja haya sido acordada por los servidos sanitarios oficiales y tenga una duración de más de veinte días consecutivos».

Las diversas modificaciones operadas desde entonces hasta la última llevada a cabo, primero por el RDL 3/2012, de 10 de febrero, de medidas urgentes de reforma del mercado laboral, y poco después, tras su tramitación parlamentaria como proyecto de ley, por la Ley 3/2012, de 6 de julio, han afectado a partes concretas del precepto, pero no han alterado la posibilidad de extinción por bajas, aun jutificadas, por contingencias comunes $^{3}$. La norma será derogada por el RDL 4/2020, de 18 de febrero, publicada en el BOE el 19 y con entrada en vigor el 20.

En este artículo partiré de algunas modificaciones de importancia incorporadas en la reforma laboral de 2012. Me detendré a continuación

ra redacción del precepto, subrayan que la supresión de esta causa de despido objetivo, tras la entrada en vigor del RDL 4/2020, «invita a efectuar algunas reflexiones sobre su causa y sobre sus consecuencias, tanto con una perspectiva histórica, examinando la evolución de esta causa de despido, como con la del análisis de las razones de su establecimiento y del de las posibles causas de su derogación normativa».

${ }^{3}$ La línea tendente a ampliar las faltas de asistencia al trabajo que no merecían la connotación negativa de absentismo al no computar para su cálculo, y que operaba sobre el párrafo $2 .^{\circ}$ de la norma contenida en la letra d) del art. $52 \mathrm{ET}$, «se quebró por la Ley 35/2010, que facilitó el despido por esta causa al actuar sobre su supuesto de hecho definitorio [párrafo $1 .^{\circ}$ de la letra $d$ ) del art. 52 del ET], rebajando el índice de absentismo total de la plantilla del centro de trabajo al 2,5 por 100 (disposición adicional vigésima). Algunos grupos parlamentarios habían solicitado la supresión del índice de absentismo colectivo porque dificultaba notablemente la aplicación de esta causa de despido objetivo. La interpretación del Tribunal Supremo aclararía que las ausencias justificadas, necesariamente intermitentes, no computables no lo eran tanto a efectos del cálculo de los porcentajes de absentismo individual del trabajador, como del colectivo de la plantilla - no equivalente a la inasistencia genérica- (SSTS de 23 de enero y de 18 de septiembre de 2007) hasta su supresión en 2012». Cfr. M. ${ }^{a}$ E. CASAS y M. RodríguEZ-PIÑERO, «El Estatuto de los Trabajadores...», op. cit. 
con brevedad en algunas resoluciones judiciales y pasaré a continuación al examen de la STC, finalizando con la explicación sobre el RDL 4/2020. Baste ahora apuntar que la STC es interesante desde el punto de vista no solo jurídico, sino también social, ya que permite ver de qué forma algunas de las cuestiones planteadas ya estaban latentes en aquella reforma, y como después han llegado, aunque sea por vía indirecta en cuanto que la cuestión abordada era si estábamos o no en presencia de un despido por causa de discapacidad, hasta el Tribunal de Justicia de la Unión Europea (TJUE); por no hablar de los problemas prácticos de aplicación de la norma en punto a determinar si podían computarse las bajas producidas en periodos anteriores a la entrada en vigor del RDL 3/2012, o, más adelante, si el periodo de dos meses continuos para el cómputo de las ausencias debía calcularse dentro del de los doce meses anteriores o bien este último era distinto del anterior y por ello el cómputo alcanzaría hasta catorce meses, y si el cómputo de los cuatro meses discontinuos podía reducirse si en un periodo inferior ya se había producido el 25 por 100 de faltas aun jutificadas de asistencia al trabajo ${ }^{4}$.

\section{LAS MODIFICACIONES INTRODUCIDAS EN EL ART. 52.D) DE LA LET POR LA LEY 3/2012}

Veamos en primer lugar una comparación entre la normativa vigente hasta el 11 de febrero de 2012 y las modificaciones introducidas por el Real Decreto-ley 3/2012, de 10 de febrero, de medidas urgentes para la reforma del mercado laboral.

La reforma laboral acogió una reivindicación empresarial que había sido defendida en anteriores reformas laborales en sede parlamentaria por los grupos popular, de Convergència i Unió y del Partido Nacionalista Vasco, y que solo se había acogido parcialmente en la reforma de 2010 al

\footnotetext{
${ }^{4}$ El despido por absentismo ha merecido la atención de la doctrina laboralista en monografías. Sobre las reformas introducidas por la legislación de 2010 y 2012 vid. Á. ARIAS, Absentismo Laboral, Madrid, Aranzadi Thomson Reuters, 2013. Desde una perspectiva mucho más cercana en el tiempo, y siendo según su autor «un análisis de las dudas y cuestiones interpretativas que se vienen planteando en la práctica, pero con la finalidad de precisar si su configuración jurídica responde a la finalidad y naturaleza de la institución o si, sin embargo, responde a una política que en los últimos tiempos ha venido ligada a la flexibilidad en un contexto de crisis» vid. M. Á. GómEz, El absentismo laboral como causa de despido objetivo. Puntos críticos en la redacción del art. 52.d) del Estatuto de los Trabajadores, Granada, Comares, 2019.
} 
disminuir el porcentaje de absentismo del conjunto de la plantilla del centro de trabajo necesario para poder despedir por causas objetivas a un trabajador que superara unos determinados porcentajes de absentismo a título individual. Con la reforma de 2012 desapareció la referencia al absentismo colectivo y el trabajador «quedaba solo ante el peligro», de tal manera que la extinción podía producirse cuando tuviera un absentismo, con los límites fijados en el art. 52.d) LET sobre sus causas, que alcanzara «el 20 por 100 de las jornadas hábiles en dos meses consecutivos, o el 25 por 100 en cuatro meses discontinuos dentro de un periodo de doce meses».

\begin{tabular}{|c|c|}
\hline Normativa vigente a 11 de febrero de 2012 & Real Decreto-ley 3/2012 \\
\hline $\begin{array}{l}\text { «d) Por faltas de asistencia al trabajo, aun } \\
\text { jutificadas pero intermitentes, que alcancen } \\
\text { el } 20 \text { por } 100 \text { de las jornadas hábiles en dos } \\
\text { meses consecutivos, o el } 25 \text { por } 100 \text { en cua- } \\
\text { tro meses discontinuos dentro de un perio- } \\
\text { do de doce meses, siempre que el índice de } \\
\text { absentismo total de la plantilla del centro } \\
\text { de trabajo supere el } 2,5 \text { por } 100 \text { en los mis- } \\
\text { mos periodos de tiempo. } \\
\text { No se computarán como faltas de asis- } \\
\text { tencia, a los efectos del párrafo anterior, } \\
\text { las ausencias debidas a huelga legal por el } \\
\text { tiempo de duración de la misma, el ejerci- } \\
\text { cio de actividades de representación legal } \\
\text { de los trabajadores, accidente de trabajo, } \\
\text { maternidad, riesgo durante el embarazo } \\
\text { y la lactancia, enfermedades causadas por } \\
\text { embarazo, parto o lactancia, paternidad, } \\
\text { licencias y vacaciones, enfermedad o acci- } \\
\text { dente no laboral cuando la baja haya sido } \\
\text { acordada por los servicios sanitarios oficia- } \\
\text { les y tenga una duración de más de veinte } \\
\text { días consecutivos, ni las motivadas por la } \\
\text { situación física o psicológica derivada de } \\
\text { violencia de género, acreditada por los ser- } \\
\text { vicios sociales de atención o servicios de } \\
\text { Salud, según proceda». }\end{array}$ & $\begin{array}{l}\text { «d) Por faltas de asistencia al trabajo, } \\
\text { aun jutificadas pero intermitentes, que } \\
\text { alcancen el } 20 \text { por } 100 \text { de las jornadas } \\
\text { hábiles en dos meses consecutivos, o el } \\
25 \text { por } 100 \text { en cuatro meses discontinuos } \\
\text { dentro de un periodo de doce meses. } \\
\text { No se computarán como faltas de asis- } \\
\text { tencia, a los efectos del párrafo ante- } \\
\text { rior, las ausencias debidas a huelga legal } \\
\text { por el tiempo de duración de la misma, } \\
\text { el ejercicio de actividades de representa- } \\
\text { ción legal de los trabajadores, acciden- } \\
\text { te de trabajo, maternidad, riesgo durante } \\
\text { el embarazo y la lactancia, enfermedades } \\
\text { causadas por embarazo, parto o lactan- } \\
\text { cia, paternidad, licencias y vacaciones, } \\
\text { enfermedad o accidente no laboral cuan- } \\
\text { do la baja haya sido acordada por los } \\
\text { servicios sanitarios oficiales y tenga una } \\
\text { duración de más de veinte días conse- } \\
\text { cutivos, ni las motivadas por la situación } \\
\text { física o psicológica derivada de violencia } \\
\text { de género, acreditada por los servicios } \\
\text { sociales de atención o servicios de Salud, } \\
\text { según proceda». }\end{array}$ \\
\hline
\end{tabular}

El texto reformado del art. 52.d) LET sería nuevamente modificado durante la tramitación parlamentaria acordada por el Congreso del RDL 3/2012 convertido en proyecto de ley.

Parecía que con el RDL se había dado satisfacción a una antigua reivindicación de amplios sectores empresariales, pero el grupo parlamenta- 
rio popular (y también el de Convergència i Unió) presentó una enmienda que matizaba la aplicación de esa extinción. Junto a una mejora de concreción de las causas que no podrían computarse a efectos del cálculo del absentismo, con inclusión expresa de los tratamientos médicos de cáncer y de la «enfermedad grave», se añadió la incorporación al art. 52.d) LET de la posibilidad de extinguir el contrato por absentismo por faltas justificadas pero intermitentes que llegaran al 20 por 100 de jornadas hábiles en dos meses consecutivos (redacción ya existente con anterioridad y que no ha sido modificada) pero siempre y cuando, y aquí viene la importante modificación, además de ese cómputo «el total de faltas de asistencia (del trabajador) en los doce meses anteriores alcance el cinco por ciento de las jornadas hábiles». Por consiguiente, y en una interpretación literal de la norma, parecía que el despido por absentismo solo podría producirse una vez que pudiera computarse un periodo anual laboral del trabajador. La enmienda fue tomada en consideración e incorporada al texto definitivo, que quedó así:

«d) Por faltas de asistencia al trabajo, aun jutificadas pero intermitentes, que alcancen el 20 por 100 de las jornadas hábiles en dos meses consecutivos siempre que el total de faltas de asistencia en los doce meses anteriores alcance el cinco por ciento de las jornadas hábiles, o el 25 por 100 en cuatro meses discontinuos dentro de un periodo de doce meses.

No se computarán como faltas de asistencia, a los efectos del párrafo anterior, las ausencias debidas a huelga legal por el tiempo de duración de la misma, el ejercicio de actividades de representación legal de los trabajadores, accidente de trabajo, maternidad, riesgo durante el embarazo y la lactancia, enfermedades causadas por embarazo, parto o lactancia, paternidad, licencias y vacaciones, enfermedad o accidente no laboral cuando la baja haya sido acordada por los servicios sanitarios oficiales y tenga una duración de más de veinte días consecutivos, ni las motivadas por la situación física o psicológica derivada de violencia de género, acreditada por los servicios sociales de atención o servicios de Salud, según proceda.

Tampoco se computarán las ausencias que obedezcan a un tratamiento médico de cáncer o enfermedad grave».

Por su parte, el grupo socialista presentó una enmienda, no tomada en consideración, en la que recuperaba la obligación de tomar en consideración el índice de absentismo de la plantilla (2,5 por 100) y no solo del trabajador individualmente considerado para poder extinguir el contrato al amparo del art. 52.d) por faltas aun jutificadas de asistencia al trabajo. 


\section{EL DESPIDO POR ABSENTISMO EN LA JURISPRUDENCIA DEL TJUE Y DEL TS}

\section{TJUE}

No había sido con anterioridad la temática de la extinción del contrato por causas objetivas, y más concretamente la extinción regulada en el art. 52.d) LET debida a faltas aun jutificadas de asistencia al trabajo (con los límites que se ha ido fijando desde el origen de la norma y pasando por las modificaciones experimentadas), de especial atención en sede judicial, muy probablemente porque la regulación normativa, al menos en sus orígenes, no incentivaba a la parte empresarial a acudir a esa vía para proceder a la extinción de los contratos laborales, reparando en que era necesaria la suma del absentismo individual y del colectivo, en los términos fijados en el citado precepto, para poder plantear la extinción, teniendo en consideración además el amplio abanico de supuestos excluidos de la toma en consideración a efectos del cómputo numérico y dejando reducida en la práctica el supuesto a las bajas por enfermedad común de duración inferior a veinte días consecutivos. Tampoco la reforma de 2012 supuso un incremento relevante en sede judicial de los litigios por tal despido objetivo, aun cuando la importancia se derivó hacia la posible discriminación cuando se reconociera a la parte trabajadora afectada por una situación de discapacidad, siendo el punto de referencia fundamental al respecto la sentencia del TJUE de 18 de enero de 2018, asunto C-270/16, en el conocido como caso Ruiz Conejero, planteado como cuestión prejudicial por el Juzgado de lo Social núm. 1 de Cuenca.

El TJUE acepta, y no lo hace ahora por primera vez, sino que ya lo aceptó plenamente en el caso HK Dammark, que combatir el absentismo laboral constituye una «finalidad legítima» que requiere la norma comunitaria, que puede perfectamente inscribirse dentro del margen de apreciación de que disponen los Estados miembros para regular una determinada norma en la que se primen unos objetivos sobre otros en materia de política social y de empleo, así como de las medidas que deban contribuir a ello, pero inmediatamente, y aquí empieza el «sí pero no, no pero sí ... sino todo lo contrario», recuerda que hay que comprobar si los citados medios «son adecuados y no van más allá de los necesario para alcanzarla», siendo en los apartados 46 a 51 de la Sentencia cuando el Tribunal le proporciona orientaciones al juzgador nacional sobre cómo resolver el litigio... en un sentido o en otro. 
Repárese por ello en las siguientes tesis del TJUE: «corresponde al órgano jurisdiccional remitente verificar si los datos numéricos recogidos en el art. 52.d) LET, se han concebido efectivamente para responder a la finalidad de combatir el absentismo laboral, sin incluir ausencias meramente puntuales y esporádicas»; debe tomar igualmente en consideración «todos los demás aspectos relevantes para efectuar dicha verificación, en particular los costes directos e indirectos que han de soportar las empresas como consecuencia del absentismo laboral» $\cdot$; le corresponde verificar si el citado precepto «al establecer el derecho al despido de los trabajadores en caso de faltas de asistencia intermitentes por causa de enfermedad durante un determinado número de días, tiene, respecto a los empresarios, el efecto de un incentivo para la contratación y el mantenimiento en el puesto de trabajo», en fin, con el objeto de examinar si los medios previstos en el citado precepto «no van más allá de lo necesario para alcanzar la finalidad establecida», procede situarlo «en el contexto en que se inscribe y tomar en consideración el perjuicio que puede ocasionar a las personas a que se refiere». Igualmente, cuando se valore la proporcionalidad de tales medios, el juzgador «no deberá ignorar tampoco el riesgo que corren las personas afectadas por una discapacidad, que en general encuentran más dificultades que los trabajadores sin discapacidad para reincorporarse al mercado de trabajo y tienen necesidades específicas ligadas a la protección que requiere su estado».

Tras estas orientaciones formuladas, el TJUE recuerda el contenido de la normativa española aplicable y las tesis del Gobierno español respecto a la conveniencia, con dicho precepto, de mantener un equilibrio «entre los intereses de la empresa y la protección y seguridad de los trabajadores». En tales observaciones (vid. apartado 53), el Gobierno expone que las últimas modificaciones del art. 52.d) LET fueron para incluir como ausencias justificadas y que no pueden tomarse en consideración para la extinción aquellas que obedezcan a un tratamiento médico de cáncer o enfermedad grave, manifestando que «precisamente, los trabajadores con discapacidad pueden encontrarse habitualmente en alguno de estos supuestos, en cuyo caso las ausencias atribuibles a la discapacidad no se computarán a efectos de un despido por faltas de asistencia intermitentes al trabajo». 


\section{TS}

Me refiero a las Sentencias de 28 de enero y de 4 de febrero de 2019 (RCUD 667/2017 y 1113/2017, respectivamente). El interés de ambas resoluciones judiciales radica en cómo abordan cuestiones concretas relativas a la aplicación del art. 52.d) LET. No es en puridad nueva doctrina, ya que en ambas sentencias hay remisión a otras anteriores, pero me ha parecido interesante su análisis dado que no son muchos los casos de los que ha conocido el alto tribunal en esta materia.

A) El primer litigio encuentra su origen en la demanda interpuesta por una trabajadora, en procedimiento por despido, tras la decisión de la empresa de extinguir el contrato de trabajo por causas objetivas tras diversos periodos de baja de aquella por enfermedad.

Con prontitud centra el TS la cuestión a dilucidad, cual es «el problema referido al modo temporal en el que han de computarse las ausencias intermitentes y justificadas al trabajo por enfermedad cuando superan el 20 por 100 de las jornadas hábiles en un periodo de dos meses, cuando en un año anterior esas ausencias también alcanzan el 5 por 100 de dichas jornadas, y más específicamente si ese tiempo de doce meses ha de contarse hacia atrás desde la fecha del despido para hallar ese porcentaje, o por el contrario deberá hacerse desde los dos meses de cómputo que se han tenido en cuenta, también hacia atrás»; o lo que es lo mismo, y visto desde otra perspectiva, si se computa sobre doce o catorce meses, ya que en un caso sí entran los dos meses en los que debe cumplirse el 20 por 100 de ausencias de jornadas hábiles, y en el segundo no ocurre así, sino que el cómputo se inicia a partir de la finalización del segundo mes tomado en consideración para el cómputo del citado 20 por 100.

Según los hechos probados de la sentencia de instancia, recogidos en el antecedente de hecho primero de la sentencia del TS, la decisión de la empresa se adoptó porque la suma de diversas bajas por enfermedad, todas ellas debidamente justificadas con parte médico, superaban el 20 por 100 de jornadas hábiles, y también, en cuanto que así debe cumplirse igualmente por mor de lo dispuesto en el art. 52.d) LET, las ausencias de la trabajadora durante «los doce meses anteriores al despido» superaban el 5 por 100 de las jornadas hábiles de trabajo. Con los datos facilitados por la empresa, y de acuerdo con el cómputo operado según la opción de «doce meses», la trabajadora tenía un absentismo «del 37,5 por 100 respecto de las jornadas 
hábiles existentes en los dos meses anteriores al despido», y del 11,96 por 100 de las jornadas hábiles en los doce meses anteriores a este.

La estimación de la demanda en instancia se debió a cómo entendió el juzgador que debía computarse el periodo del 5 po 100 que debía ser «doce meses hacia atrás desde los dos meses computados para hallar el 20 por 100 de ausencias injustificadas, lo que en el caso no se cumplía, porque no constaba la existencia de ninguna ausencia».

La tesis de la sentencia de suplicación, cuyos razonamientos son catalogados por el TS, y coincido con su apreciación, de «extensos y cuidados», se sitúa en la misma línea. La Sala hace suya, después de una amplia y extensa fundamentación de su tesis, la defendida en la sentencia de instancia, subrayando que «la tesis del recurso en materia de cómputo de los tiempos en los que han de localizarse las faltas de asistencia al trabajo cobija un duplicado cómputo del absentismo que se localiza en los dos meses anteriores a la decisión empresarial extintiva del contrato de trabajo».

Interpretación integradora de la norma y tendente a diferenciar claramente el periodo de los dos meses continuos durante el que deben computarse un número de ausencia determinado, por una parte, y el del periodo anual, que podría convertirse en precepto de escasa importancia práctica si se computaran los citados dos meses anteriores al despido y cuando las faltas de ausencia en estos fueran un número considerable, es la defendida en instancia y en suplicación, pero no tendrá acogida por el TS, que aceptará la tesis recogida en la sentencia aportada de contraste, la del TSJ de Madrid de 22 de junio de 2016, que reitera doctrina de la propia Sala (Sentencia de 18 de noviembre de 2014), y defiende la tesis a la que se acogió la parte empresarial en la sentencia ahora objeto de comentario: «Este Tribunal entiende que ambas formas de cálculo tienen en común que las ausencias laborales han de computarse en un periodo único de doce meses. Por dos razones. La primera consiste en que, si se siguiera el criterio de la sentencia impugnada, la duración del periodo de ausencias a considerar sería variable en cada caso, en función de la fecha en que hubieran tenido lugar las bajas computadas en el periodo de dos meses que debe reunir un 20 por 100 de ausencias laborales. La segunda razón radica en que no sería coherente que la segunda fórmula de cálculo de ausencias tomara en cuenta un periodo de doce meses mientras la primera fórmula de cálculo considerara un periodo mayor, pues la única diferencia entre ambas fórmulas se refiere al volumen de ausencias, según se produzcan en meses consecutivos o discontinuos, pero no a los meses totales de ausencias computables, que son comunes en ambos casos: «dentro de un periodo de doce meses». 
En este punto, y debatiéndose pues la interpretación del art. 52.d) LET, cuya infracción se alega en el RCUD al amparo del art. 207.e) LRJS, la Sala del Alto Tribunal seguirá su doctrina sentada en Sentencia de 19 de marzo de 2018, previa a manifestación de que nada hubiera impedido al legislador considerar diferentes periodos de cómputo para las faltas durante dos meses consecutivos (o cuatro discontinuos) y para aquellas que se tuvieran en cuenta durante doce meses, y considerar que el texto normativo vigente solo opera con una «realidad única», que es la de los doce meses anteriores a la fecha del despido, o lo que es lo mismo, el tiempo común de cómputo, «es el módulo de un año a contar desde el despido hacia atrás, durante el que deberán haberse producido las circunstancias que el precepto regula».

Tal como se argumentó en la Sentencia de 19 de marzo de 2018, y a la que la Sala se atiene «por razones de seguridad jurídica (art. 9.3 CE)», «el primer plazo (que denominaremos corto) de dos meses o cuatro según el caso, y el segundo plazo - que es el discutido- (que denominaremos largo) de doce meses, es claro que han de coincidir en un único periodo de doce meses, aunque el criterio para su cómputo sea distinto respecto al primero en función de las bajas computables que hubieren tenido lugar. La diferencia entre ambos periodos radica exclusivamente en el volumen de ausencias que podrá variar según se produzcan en meses consecutivos o discontinuos, pero no va a variar respecto a los meses totales de ausencias computables, que son comunes de doce».

Dado que de conformidad con esta doctrina, la trabajadora despedida superó tanto el porcentaje previsto para dos meses consecutivos como el establecido para el cómputo anual, se estimará el RCUD a los efectos de considerar la existencia de causa y devolviendo las actuaciones al TSJ para que resuelva sobre la posible exclusión del cómputo de dichas bajas, si encajaran justamente dentro de alguno de los supuestos de tal exclusión previstos en la norma, con las consecuencias legales pertinentes.

B) La segunda sentencia dictada por el TS, en fecha 4 de febrero, encuentra su origen en sede judicial con la presentación de una deman$\mathrm{da}$, en procedimiento por despido, por parte de un trabajador, tras la decisión empresarial de proceder a la extinción del contrato por causas objetivas como consecuencia de bajas, justificadas, de asistencia al trabajo, que a su parecer superaban el porcentaje del 25 por 100 en cuatro meses discontinuos, computando las ausencias al trabajo «de fecha a fecha» (de cada baja), es decir, desde que se produjo la primera hasta la última, y no por meses naturales, siendo la consecuencia de la opción empresarial que el 
periodo de cómputo era inferior a cuatro meses. La Sala estimará el RCUD de la parte trabajadora, en contra del criterio defendido en el preceptivo informe del Ministerio Fiscal y que abogaba por su improcedencia.

La tesis de instancia y de suplicación se centra en la importancia del dato cuantitativo del 25 por 100 de ausencias en el cómputo anual, considerando indiferente, y de ahí sus resoluciones, que cómputo de las mismas (efectuado de fecha a fecha de cada una) fuera inferior a cuatro meses, «con independencia de que los meses se computaran de fecha a fecha» como estableció la Sentencia del TS de 9 de diciembre de 2010 (RCUD 842/2010).

En esta sentencia del alto tribunal, y acudiendo, ante la controversia suscitada, «al criterio que pueda derivarse de la finalidad del precepto en cuestión», se llega a esta conclusión» «En efecto, el despido por faltas de asistencia al trabajo, aunque estén justificadas, tiene por objeto luchar contra el absentismo, cuya influencia negativa en la marcha normal de la relación laboral es evidente, máxime si el general de la empresa rebasa el 5 por 100 situación cuya corrección exige de medidas al efecto, aunque sean traumáticas. Ello determina que la solución que hayamos de adoptar sea la más acorde con esa finalidad. Pues bien, aceptando el criterio de los meses naturales, como ha resuelto la sentencia invocada de contraste, determinados días de falta de asistencia al trabajo pueden quedar fuera del cómputo - como ocurrió en el caso allí enjuiciado - cuando la falta de asistencia al trabajo se produce en los días finales de un mes y primeros del siguiente, en cuyo caso estos últimos no se computarían. Tal conclusión sería abiertamente contraria a la finalidad de la norma. Debiendo en consecuencia aceptarse el criterio de la recurrida -cómputo por meses de fecha a fecha que encuentra apoyo en el precepto del art. 5 del Código Civil y es acorde con la finalidad de la norma». Dicha sentencia también será aportada en el RCUD para defender la tesis de la toma en consideración de los periodos de cómputo por meses.

Con prontitud centra el TS la cuestión a resolver en el caso enjuiciado, y que ya ha quedado bien delimitada en mi explicación anterior: se trata de abordar el problema «referido al modo temporal en el que han de tenerse en cuenta las ausencias intermitentes y justificadas al trabajo por enfermedad durante cuatro meses discontinuos en un periodo de doce, y más específicamente si esos cuatro meses han de computarse por meses naturales o de fecha a fecha, todo ello en el marco de aplicación del art. 52.d) ET en un despido por las causas objetivas previstas en ese precepto, lo que además comportará decidir si cabe imputar el porcenta- 
je de las referidas ausencias en un periodo de tiempo inferior a los cuatro meses previstos en la norma».

En la tesis estimatoria del RCUD la Sala acude a su doctrina sentada en la ya lejana en el tiempo Sentencia de 5 de octubre de 2005 (RCUD 3468/2004), en la que se realiza una explicación general de los «elementos básicos» del art. 52.d) LET, obviamente en la redacción entonces vigente, destacando, a lo que ahora interesa al objeto de mi explicación, que la norma estaba refiriéndose de forma clara y manifiesta, a los efectos del primer cómputo del periodo de ausencias, al integrado «por dos o cuatro meses, y que a ellos se refiere el porcentaje».

Igualmente, la Sala hará suya la tesis anteriormente expuesta por la Sentencia de 9 de febrero de 2010. La conclusión a la que llega la Sala es que la finalidad de la norma solo se cumple tomando en consideración cuatro meses naturales, discontinuos, a efectos del cómputo del 25 por 100 de faltas aun jutificadas de ausencia al trabajo, y no de fecha a fecha únicamente computando cada periodo de baja, ya que de hacerlo así se desvirtuaría aquella finalidad, tal como ocurrió, subraya el TS, en la sentencia recurrida, ya que «de hecho se aprecia como causa válida para el despido objetivo llevado a cabo por la empresa el hecho de que las bajas se produjeran durante tres meses intermitentes, no cuatro, computados de fecha a fecha». Corolario de todo lo anterior es la declaración de improcedencia del despido.

\section{ANÁLISIS DE LA STC NÚM. 118/2019, DE 26 DE OCTUBRE}

1. Procede ya entrar en el análisis de la STC, que desestima la cuestión de inconstitucionalidad planteada por el JS núm. 26 de Barcelona mediante Auto de 8 de abril de 2019. En realidad, se trata de la segunda cuestión de inconstitucionalidad sobre la misma temática, ya que una anterior se planteó por el mismo JS por Auto de 13 de junio de 2018, por posible vulneración de los arts. 15, 35 y 43 CE por parte del art. 52.d) LET, que no fue admitida por Auto núm. 9/2019, de 12 de febrero, acogiendo el TC la tesis de la fiscalía de interesar la inadmisión de la cuestión «por incorrecta formulación del juicio de relevancia y por resultar notoriamente infundada». En su argumentación, sustancialmente idéntica en cuanto al fondo con la que expondrá en el litigio que dará lugar a la Sentencia de 16 de octubre, expuso que «desde la perspectiva del art. $35 \mathrm{CE}$, no se puede considerar que el precepto cuestionado resulte contrario al derecho al tra- 
bajo y al principio de estabilidad en el empleo, pues, si bien es cierto que el legislador ha adoptado, mediante el art. 52.d) LET, una medida legislativa que limita el derecho al trabajo, lo ha hecho con base en un derecho constitucional (art. $38 \mathrm{CE}$ ), con una finalidad legítima, con la correspondiente indemnización, y ponderando los intereses en conflicto, especialmente a través de las correspondientes excepciones a la cláusula general».

En los antecedente se explican los hechos que están en la base del litigio y que se sintetizan en la superación de los porcentajes de bajas aun jutificadas de asistencia al trabajo [art. 52.d) LET] por parte de una trabajadora que prestaba su servicios en el sector de la atención telefónica, en un periodo de dos meses continuos y dentro de un periodo de doce meses. Más exactamente, en los meses de abril y mayo de 2017 había faltado nueve días de los cuarenta hábiles a efectos laborales (22,50 por 100), y durante los doce meses en los que se incluye este periodo bimensual las ausencias habían sido de dieciséis (7,84 por 100).

En el auto, y destaco aquello que me parece más relevante para la resolución que adoptará después el TC, el juzgador se plantea «la posible contradicción del precepto legal cuestionado con los derechos a la integridad física (art. $15 \mathrm{CE}$ ), al trabajo (art. 35.1 CE) y a la protección de la salud (art. 43.1 CE), valorando que la regulación legal del despido objetivo por absentismo podría condicionar el comportamiento de los trabajadores que, ante el temor de perder su puesto de trabajo, pudieran orillar la atención de su salud e integridad física o emocional, acudiendo a su puesto y asumiendo así un sacrificio en absoluto exigible, que incluso puede complicar la evolución de su enfermedad», y que «al haber prescindido la actual regulación del índice colectivo de absentismo, difícilmente puede justificarse la previsión legal en el interés empresarial de defender la productividad. Cierto es que para conciliar ambos bienes en conflicto, la salud del trabajador y la productividad empresarial, se han excluido del cómputo las bajas médicas prolongadas y las derivadas de graves enfermedades. No obstante, quizás la ponderación de intereses implícita en la regulación legal pudiera no ser suficiente para proteger situaciones derivadas de enfermedades crónicas, de curso fluctuante, especialmente limitantes en los periodos de agudización sintomática. Dan lugar a breves pero reiterados periodos de incapacidad temporal, cuyo diagnóstico la empresa ni siquiera debería conocer».

2. En la fundamentación jurídica de la sentencia se partirá de la desestimación de la tesis de la abogacía del Estado de no entrar en la vulneración alegada del art. 35.1 CE por no haberla razonado suficientemente el 
auto de la cuestión prejudicial. A diferencia de la inadmisión anterior, en esta ocasión el TC admite que el auto contiene «exposición mínima pero suficiente de los motivos por las que el juzgador entiende que el art. 52.d) LET podría vulnerar el derecho al trabajo (art. 35.1 CE), estrechamente conectados, desde luego, a los razonamientos en los que descansa la duda de constitucionalidad sobre la pretendida vulneración de los derechos a la integridad física (art. 15 CE) y a la protección de la salud (art. 43.1 CE)», por lo que procederá abordar la posible contradicción de la norma legal tanto con los arts. 15 y 43.1 como con el art. 35.1 CE.

3. Una vez despejado el óbice procesal formal, y delimitado en el fundamento jurídico tercero el valor jurídico del art. 52.d) LET y la limitación que puede suponer, debidamente justificada, a varios derechos constitucionales de la persona trabajadora, señaladamente el derecho al trabajo, se procede al examen de la posible vulneración del art. $15 \mathrm{CE}$, la integridad física, del que el TC subraya que «aparece vinculada en los razonamientos del auto de planteamiento a la preservación de la salud del trabajador», aceptando, con amplia cita de algunas sentencias anteriores, la existencia de «una cierta conexión» entre el derecho a la integridad física del art. 15.1 y el derecho a la salud reconocido en el art. 43.1, «pero sin que ello pueda llevar a identificar o confundir ambos derechos». Para el TC, la afectación del art. 15.1 CE solo podría producirse cuando la actuación empresarial en relación con las bajas por enfermedad de la persona trabajadora pudiera provocar un «peligro grave y cierto para la salud del afectado», y en el litigio afectado no se produce a su parecer, ya que lo único que hace el empleador es que «se limita a autorizar el despido para el caso de que se supere un número de faltas de asistencia al trabajo intermitentes, justificadas o no, en un determinado periodo de tiempo» ${ }^{5}$.

${ }^{5}$ «El derecho a la salud del art. 43.1 CE se ha vinculado por la jurisprudencia constitucional a la obligación del legislador de regular las condiciones y términos para el acceso a prestaciones y servicios sanitarios. Por ello, la STC 118/2019 ha estimado que el art. 52.d) del ET no incidía en el régimen de acceso y contenido de la asistencia sanitaria. Destaca, además, que el precepto estatutario excluía el cómputo de las enfermedades de mayor duración o gravedad, aparte de las derivadas de situaciones vinculadas al género. La sentencia no descarta que dicho precepto pudiera provocar una tendencia del trabajador a acudir al trabajo pese a sufrir una enfermedad o indisposición, por el temor a perder el puesto de trabajo con el riesgo de comprometer su salud, pero entiende que ello no significaba que el precepto estuviera «desprotegiendo la salud de los trabajadores» al haber identificado el legislador «la excesiva morbilidad intermitente como una de las causas principales de ausencias al trabajo».

Ese razonamiento, al igual que la referencia «al legítimo interés de la empresa de paliar la onerosidad de las ausencias al trabajo, que se conecta con la defensa de la productividad», 
En un razonamiento circular, que será fuertemente criticado en el voto particular discrepante del magistrado Fernando Valdés y al que se adhiere el magistrado Cándido Conde-Pumpido, se justifica la inexistencia de la vulneración porque no existe conexión entre el derecho a la integridad física y la actuación empresarial, ya que la causa del despido «no es en este caso el mero hecho de estar enfermo el trabajador, sino la reiteración intermitente del número de faltas de asistencia al trabajo, justificadas o no, que hayan tenido lugar en un determinado periodo de tiempo - absentismo laboral一».

4. Desestimada la vulneración del art. 15.1 CE, la Sala se adentra en el examen de la alegación en el mismo sentido realizada con respecto al art. $43 \mathrm{CE}$, la protección de la salud, con argumentos que completarán las tesis anteriormente defendidas.

La tesis de que la medida regulada en el art. 52.d) es un instrumento legítimo de lucha contra el absentismo y una medida proporcionada respecto a la limitación que pueda sufrir el derecho constitucional al trabajo, estará en la base nuevamente de la argumentación con la que se desestimará la tesis del juzgador de instancia respecto a que la vulneración del art. 43 podría darse porque la posible pérdida del puesto de trabajo llevaría a los trabajadores a acudir al trabajo aun estando enfermos, «con el riesgo de comprometer su salud».

Aunque el TC acepta que «no sea descartable que la regulación controvertida pudiera en algún caso condicionar la actuación del trabajador en el sentido aventurado por el órgano judicial», no considera en modo alguno que se desproteja la salud de las personas trabajadoras, ya que el art. 52.d) LET «se limita a regular la posibilidad de que el empresario extinga el contrato de trabajo por faltas de asistencia al trabajo, aun jutificadas pero intermitentes, que alcancen unos determinados porcentajes, y que pueden derivar de enfermedades de corta duración del trabajador — hayan dado lugar o no a la expedición de partes de baja médica-. El legislador identifica la excesiva morbilidad intermitente como una de las causas principales de ausencias al trabajo».

no justifican convincentemente el desequilibrio que podía suponer el sacrificio de la protección y la salud de los trabajadores. La sentencia debería haber introducido matices, criterios interpretativos o condicionamientos que justificaran ese eventual sacrificio, sobre todo en los casos en que se demostrara que ello estaba ocurriendo efectivamente. Es muy dudoso, dado su origen preconstitucional, que la derogada causa de despido se propusiera la mejora de la productividad, y se ha de tener en cuenta que en la productividad inciden también otras ausencias del trabajador cuyo cómputo el precepto excluía. Cfr. M. ${ }^{a}$ E. CASAS y M. RodRíGUEZ-PIÑERO, «El Estatuto de los Trabajadores...», op. cit. 
A mi parecer, el TC no responde a las preguntas o cuestiones formuladas, sino que parte del presupuesto previo de la validez del art. 52.d) LET y a partir de esta premisa previa construye su respuesta sobre cada precepto cuestionado. El valor atribuido a la defensa de la productividad, sin que el TC haga ninguna reflexión más concreta de cómo puede afectar la situación de un trabajador en una gran, mediana o pequeña empresa, y como un solo trabajador puede dañar la misma, le lleva a concluir que el legislador ha pretendido, y por supuesto lo ha conseguido a juicio de la mayoría de miembros de la Sala (en sentido radicalmente contrario los votos particulares discrepantes) mantener el equilibrio entre «el legítimo interés de la empresa de paliar la onerosidad de las ausencias al trabajo [...] y la protección de la seguridad y salud de los trabajadores».

No existe tampoco vulneración del derecho al trabajo (art. 35 CE), aun cuando el auto haya aportado a favor de su tesis el Convenio núm. 158 de la OIT de 1982 sobre la terminación de la relación de trabajo por iniciativa del empleador, y más exactamente el art. 6.1 que dispone que «la ausencia temporal del trabajo por motivo de enfermedad o lesión no deberá constituir una causa justificada de terminación de la relación de trabajo», y también haya argumentado, con lógica social, que podría haber otros mecanismos menos radicales, pactados en sede colectiva, para evitar el coste que le pueda suponer a una empresa una o más situaciones de bajas laborales aun jutificadas.

Las tesis de las sentencias de 2014 y 2015 sobre la validez constitucional de la reforma laboral de 2012 vuelven a aparecer con fuerza en esta ocasión, refiriéndose al margen que tiene el legislador para adoptar las decisiones que considere más razonables para su política laboral relacionada con el art. 35 CE. Tras afirmar, y no creo que el debate se haya centrado en modo alguno en esta cuestión, que la norma cuestionada no presci de del elemento de causalidad del despido, sino que dota a la regulación de extinción por absentismo de «objetividad y certidumbre», pondera adecuadamente los intereses en juego y permite la revisión judicial, y vuelve sobre sus pasos al insistir una vez más que la limitación del derecho al trabajo «se encuentra justificada por el art. $38 \mathrm{CE}$ », ya que de esta manera se da debido cumplimiento al «objetivo legítimo de paliar el gravamen económico que las ausencias al trabajo suponen para las empresas».

No hay contradicción, siempre según el TC, entre nuestra norma legal y el convenio internacional de la OIT, y aun cuando se recuerda en todo caso se trataría de una juicio de aplicabilidad, es decir, «control de convencionalidad $[. .$.$] que pertenece a la legislación ordinaria», acaba entran-$ 
do en su análisis para poner de manifiesto que el apartado 2 del art. 6 permite «establecer limitaciones» a la aplicación del apartado 1 , y una de ellas puede ser «la defensa de la productividad», con una nueva mención a que esta «puede verse comprometida por el incremento de costes directos e indirectos que han de soportar las empresas como consecuencia de las ausencias al trabajo, aun justificadas pero intermitentes, acaecidas en un periodo determinado, conforme a las previsiones del art. 52.d) LET».

Curiosa interpretación que efectúa a mi parecer el TC de cómo debe interpretarse el apartado 2 del art. 6, convirtiéndolo no en aquello que razonablemente debería ser, una concreción de qué se entiende por ausencia temporal del trabajo y los requisitos requeridos para su debida justificación (y por tanto protección), sino en un mecanismo limitador del derecho reconocido en el párrafo anterior.

5. En definitiva, para el TC no hay vulneración alguna de preceptos constitucionales, sino solo una limitación del derecho constitucional al trabajo debidamente justificada. Y si al principio la fundamentación jurídica se iniciaba con una exposición mucho más doctrinal que jurisprudencial, o al menos de jurisprudencia constitucional, el final no le va a zaga, aunque el trabajador siga pensando que debe ir al trabajo aunque sea enfermo porque en caso contrario puede llegar a ser despedido si el empleador así lo considera oportuno. Para el TC, y aquí concluye la sentencia: «En suma, debemos descartar que el precepto legal cuestionado resulte contrario al art. 35.1 CE, pues si bien es cierto que el legislador ha adoptado una medida que limita el derecho al trabajo, en su vertiente de derecho a la estabilidad en el empleo, lo ha hecho con una finalidad legítima, evitar el incremento indebido de los costes que para las empresas suponen las ausencias al trabajo, que encuentra fundamento constitucional en la libertad de empresa y la defensa de la productividad (art. $38 \mathrm{CE}$ ). Se han ponderado los derechos e intereses en conflicto, especialmente a través de las señaladas excepciones a la cláusula general que permite la extinción del contrato de trabajo por absentismo, así como mediante el establecimiento de la correspondiente indemnización al trabajador en caso de que el empresario opte por la decisión extintiva, que en todo caso puede ser impugnada ante la jurisdicción social. A esta corresponde controlar que la decisión empresarial se ajusta a los presupuestos establecidos en el art. 52.d) LET y que la aplicación del precepto en el caso concreto no va más allá de lo necesario para alcanzar la finalidad legítima de proteger los intereses del empleador frente a las faltas de asistencia del trabajador a su puesto de trabajo, cuando alcancen la duración establecida por la norma». 
6. Los tres votos particulares son radicalmente discrepantes, si bien uno de ellos, el suscrito por el magistrado Juan Antonio Xiol, se limita a manifestar su acuerdo con las tesis expuestas en los dos restantes. Procede por ello entrar en el análisis de cada uno de ellos.

En primer lugar, me refiero al presentado por el magistrado Fernando Valdés y que cuenta con la adhesión del magistrado Cándido Conde-Pumpido. La tesis central del voto, que desarrolla extensamente, es la vulneración del derecho constitucional al trabajo, es decir, el art. 35.1 CE, previa manifestación de que la salud, o más exactamente su protección, «late y subyace intensamente en el debate de constitucionalidad que nos convoca», con aportación de doctrina constitucional que implicaría en casos semejantes «el fortalecimiento de los cánones del control de constitucionalidad», por lo que la lectura del art. 35.1 CE en su vertiente de derecho al mantenimiento y continuidad en el puesto de trabajo (no otra cosa es, añado por mi parte, la estabilidad en el empleo) «requiere de una atención profunda y tuitiva, sensible, por la necesaria protección y atención a la salud que, también en el curso de la relación laboral queda comprometida».

Procede el autor del voto a efectuar una síntesis de los argumentos más relevantes de la sentencia para desestimar la cuestión de inconstitucionalidad, que concluye lógicamente con el último párrafo de aquella, para inmediatamente exponer su parecer contrario con una dureza jurídica innegable, ya que afirma, antes de entrar en su exposición, que «hay algunas objeciones muy primarias frente a la argumentación descrita, que lamento tener que enunciar por resultar rudimentarias, pero el texto aprobado me obliga a ello, por obvias que puedan parecer», y que son en síntesis las siguientes:

a) Las amplísimas referencias a la existencia de una causa de despido objetivada en la norma no dan respuesta a la cuestión planteada, cuál es la de decidir si esa causa es «justa», ya que al actuar de esta forma no se efectúa el examen de constitucionalidad del art. 35.1 CE.

b) Que no sea justa, o que sí lo sea, no depende del número de excepciones que se prevean a la aplicación de la norma, sino de si aquella regulación, y por tanto exclusión de las excepciones, es o no constitucional, siendo así que puede plantearse, y esa es la tesis del voto, una inconstitucionalidad de la norma por, justamente, tal omisión ${ }^{6}$.

${ }^{6}$ Tesis, en la que abunda en detalle en el apartado 6, subrayando el carácter cuasi-fundamental del derecho al trabajo y la consiguiente necesidad de respetar, en cualquier desa- 
c) Insistir machaconamente en los objetivos y la finalidad de la norma, calificando de legítimo el combate contra el absentismo, no añade nada en absoluto al debate jurídico, que no es otra, recuérdese, que si la norma cuestionada respeta la CE y en el punto concreto en que ahora estamos «el derecho al trabajo y la justa causa extintiva en particular», de la misma manera que nada añade la referencia al margen de apreciación que tiene el legislador para la elaboración de normas de acuerdo con sus opciones de política legislativa, ya que sigue sin abordarse si se respeta o no el art. 35.1 CE.

d) Como tampoco es válido para justificar la «legitimidad» de la norma que se prevea, a modo de contrapeso, una indemnización para la persona trabajadora que ve extinguido su contrato, ya que primero hay que determinar, si la causa es justa, si supera en suma el test de constitucionalidad.

En definitiva, y con el deseo de sintetizar en una breve frase toda la amplia argumentación antes expuesta, se subraya que aquello que importa es el análisis del respeto al derecho constitucional al trabajo, es decir de si concurren los requisitos que avalarían la decisión del tribunal, y esta exigencia «no depende en absoluto» de los factores tomados en consideración por la sentencia, sino de «la calificación como justa o no justa», partiendo de «la veracidad de todos aquellos elementos».

El último bloque del voto particular está dedicado a criticar el desvalor que efectúa la sentencia del derecho constitucional al trabajo y que continúa la senda de las Sentencias 119/2014 y 8/2015 que validaron la reforma laboral, que ya merecieron un muy duro análisis jurídico del mismo magistrado.

No es de extrañar por ello que en el voto se haga referencia a la Sentencia 114/2014 para poner de manifiesto que el TC inició con ella «una criticable línea que, como era de esperar, desemboca en pronunciamientos como el que es ahora objeto de mi discrepancia, limitativos e insensibles con el patrimonio jurídico de los trabajadores», olvidando el contenido social de los derechos constitucionales y enfatizando el valor de la libertad de empresa y la defensa de la productividad como pilares esenciales del modelo, olvidando que en modo alguno dichos preceptos guar-

rrollo legislativo, su contenido esencial, criticando con contundencia la sentencia porque se limita a derivar el discurso hacia la existencia de otras excepciones, «sin abordar verdaderamente la legitimidad constitucionalidad de la exclusión (omisión), en contraste con la garantía de justa causa extintiva, de la que es objeto de enjuiciamiento». 
dan relación con la regulación, y más aún con la evidente limitación como se comprueba en esta sentencia, de las relaciones de trabajo y de los derechos de la parte trabajadora.

Limitaciones, que se evidencian con total claridad en el caso examinado, en el que las ausencias de la trabajadora suponen un total del 7,84 por 100 durante los doce meses anteriores al despido y dato, junto con el de las bajas del 20 por 100 en dos meses continuos de dichos doce (lo que, dicho sea no muy incidentalmente significa, y los datos aportados en la cuestión de inconstitucionalidad lo ponen claramente de manifiesto, que las ausencias, justificadas, durante los diez meses restantes fueron muy pocas), que le ha llevado al TC a considerar que se ponía en riesgo la productividad de la empresa con aplicación del art. $38 \mathrm{CE}$. Tesis que le lleva al voto particular tras criticar muy durante el planteamiento economicista y poco atento a los derechos sociales constitucionales de la sentencia, a sostener que «me parece una clara desproporción, por no calificarlo de otro modo, como lo es también desatender que se trata de ausencias justificadas, no considerar el estado de salud que está en la base y debe ser protegido, al que me referí más atrás, o, más aún, olvidar que lo que verdaderamente ampara la libertad de empresa es, en esencia, en lo nuclear, la libertad de iniciativa o el ejercicio de la actividad en condiciones de igualdad, y no otra cosa».

Para concluir que, cuando se parte de la libertad de empresa y de la defensa de la productividad como fundamento constitucional de una norma limitadora de derechos laborales, «se olvida gravemente cuando se juzga de ese modo que el interés empresarial, sea del tipo que sea, no puede legitimarse a través de medidas contrarias a los derechos constitucionales de los trabajadores (mutatis mutandis, STC 182/2005, de 4 de julio, FJ 7)».

7. El voto particular suscrito por la magistrada María Luisa Balaguer se asienta también sobre la discrepancia con la tesis de la sentencia de respeto por parte de la norma cuestionada al derecho constitucional al trabajo recogido en el art. 35.1 CE, manifestando que «comparte totalmente» las tesis del voto particular analizado con anterioridad y añadiendo únicamente que estamos en presencia de un despido no causal ya que no responde a un incumplimiento contractual de la persona trabajadora, trayendo a colación la muy lejana en el tiempo (lo que no quiere decir en absoluto que haya perdido su valor) Sentencia núm. 22/1981 de 2 de julio, en la que aparecía la referencia a que el derecho al trabajo incluye «el derecho a la continuidad o estabilidad en el empleo, es decir a no ser despedidos si no existe una justa causa». 
En línea también semejante a la del anterior voto particular, y con un cuidado apoyo en resoluciones anteriores del tribunal, la magistrada manifiesta su discrepancia con la utilización de la libertad de empresa como fundamento de la constitucionalidad de un precepto legal que acaba produciendo la extinción de la relación contractual en tanto que lo considera, el art. 52.d) LET, un instrumento legítimo para combatir el absentismo laboral, para concluir que no cabe encajar en el art. $38 \mathrm{CE}$ «cualquier actividad o decisión empresarial, y, especialmente, en lo que al presente asunto concierne, aquellas dirigidas a controlar el absentismo laboral a través de decisiones extintivas de los contratos de los trabajadores», ya que dicho control «es una cuestión que se refiere al funcionamiento interno, a la organización, pero que no adquiere una dimensión constitucional que pueda tener en cuenta el art. 38 CE. Podrá llevarse a cabo a través de distinto instrumentos o mecanismos de gestión».

Abundando en una línea que privilegia la regulación pactada de mecanismos que traten de corregir situaciones en las que el trabajador se ve afectado por estados breves de enfermedad, el voto manifiesta su asentimiento con la tesis de que ese control podrá llevarse a cabo a través de diversos mecanismos de gestión empresarial (uno de ellos, sin duda a mi parecer, el de tal regulación pactada de cómo abordar y encarar tales situaciones), y manifiesta su rechazo jurídico a que se produzca «a través de despidos carentes de causa, que tropiezan, como ya he dicho antes, con la garantía constitucional del derecho al trabajo del art. 35.1 CE, en la extensión que le ha reconocido este Tribunal, y que, en cualquier caso, no pueden encontrar nunca amparo en la libertad de empresa del art. 38 CE».

Nueva discrepancia de la magistrada con la sentencia se manifiesta en la distinta valoración del art. $43 \mathrm{CE}$, el derecho a la protección de la salud, que relaciona con el otro precepto cuestionado, el derecho a la integridad física recogido en el art. $15 \mathrm{CE}$, y nuevamente con amplio apoyo argumental en jurisprudencia anterior manifiesta, con contundencia jurídica y social, que no puede asumir que la libertad de empresa o la defensa de la productividad «puedan ser antepuestas al derecho a la integridad física y moral de los trabajadores y trabajadoras, y a un valor tan esencial como es la protección de la salud humana, que tan directa relación presenta, como ya he señalado, con los derechos del art. $15 \mathrm{CE}$ », ya que es justamente a eso «a lo que conduce el entendimiento del art. 52.d) ET que se efectúa en la sentencia de la que disiento».

Tras argumentar que de la sentencia del TJUE de 18 de enero de 2018 puede extraerse una tesis distinta a la defendida por la sentencia y ponien- 
do el acento en la relación entre ausencias justificadas como consecuencia de enfermedades atribuibles a la discapacidad de la persona trabajadoras (remito a mi examen de dicha sentencia), entra el voto en la parte argumental más novedosa en el caso examinado, ya que no se ha planteado ni en la sentencia ni en el anterior voto particular cuál es la discriminación indirecta por razón de sexo en que incurre en el art. 52.d) LET, criticando que la sentencia no haya sido capaz de apreciarla, «aun siendo incontestable su evidencia».

Antes de argumentar su tesis, la magistrada recuerda dos sentencias de indudable interés respecto a la prohibición constitucional de discriminación por razón de sexo y la protección que la CE y la normativa legal de desarrollo otorgan para evitarla. Se trata, en primer lugar, de la STC 145/1991, de 1 de julio, el muy conocido caso de las limpiadoras en el Hospital Gregorio Marañón de Madrid; en segundo término, de la STC 91/2019, de 3 de julio, relativa a la protección de los trabajadores a tiempo parcial.

La tesis de la magistrada se basa esencialmente en los datos estadísticos disponibles y que le llevan a concluir que la doble jornada de la gran mayoría de mujeres trabajadoras (laboral y de cuidados familiares) tienen una afectación especial sobre su salud e inciden negativamente sobre su actividad familiar. A tal efecto, menciona estudios realizados por la UC2M, Adecco, datos del INE sobre el número de hogares monoparentales, datos del mismo Instituto sobre el número de personas ocupadas entre dieciocho y sesenta y cuatro años con hijos propios o de la pareja menores de quince años y su efecto sobre el empleo (reducción del tiempo de trabajo), datos sobre madres trabajadoras, o no, que tienen hijos de cero a tres años, y los relativos a quienes tienen a su cuidado personas con alguna discapacidad o necesitadas de atención por tratarse de personas dependientes.

Con estos mimbres, la magistrada llega a la conclusión de que la mujer trabajadora está mucho más expuesta que el varón a posibles ausencias en el trabajo tanto por motivos de salud como por cuidado de otra persona, lo que les puede afectar mucho más que a los trabajadores varones en cuanto a la superación de los periodos de cómputo de ausencias, aun jutificadas, que pueden llevar a la extinción de su contrato de trabajo. En definitiva, concluye la magistrada que el art. 52.d) LET «incurre en una clara discriminación indirecta por razón de sexo, lo cual debería haber conducido a este Tribunal a declarar su inconstitucionalidad también (y especialmente) por este motivo». 


\section{DEROGACIÓN DEL ART. 53.D) DE LA LET. UN ARTÍCULO DE DOS LÍNEAS Y UN PREÁMBULO DE SEIS PÁGINAS 7,8}

El preámbulo de una norma es una seña de identidad de quien la aprueba. Y el muy largo preámbulo del RDL 4/2018 no creo que encuentre solo su razón de ser en el deseo del equipo del Ministerio de Trabajo y Econo-

\footnotetext{
7 Sobre los efectos de un despido producido tras la derogación del art. 52.d) y que quedará acreditado que ha sido por faltas aun justificadas de asistencia al trabajo, aun cuando se revistiera de una causa diferente, no es pacifica en la doctrina la calificación de improcedencia o nulidad del mismo. La segunda tesis ha sido defendida por el profesor Joaquín Aparicio, para quien «hay, ante todo, que destacar que en nuestro sistema no está reconocido el despido sin causa, que sería lo que aquí ocurría de modo radical. No es que se trate de una insuficiencia de causa o que esté incorrectamente alegada, es que tras la lapidaría afirmación: "Queda derogado el apartado d) del art. 52 del texto refundido de la Ley del Estatuto de los Trabajadores, aprobado por el Real Decreto Legislativo 2/2015, de 23 de octubre" las ausencias justificadas por enfermedad están expulsadas de nuestro ordenamiento como causa de despido y si el empresario las utiliza es un acto de contumaz rebeldía y desprecio del ordenamiento jurídico que pudiera ser constitutivo de una infracción muy grave sancionable, entre otros preceptos, ex art. 8.13 bis LISOS, e incluso dar lugar a una responsabilidad penal en determinadas situaciones, con la consecuencia, en todo caso, de la nulidad del despido». Cfr. J. Aparicio Tovar, «La derogación de art. 52.d) ET conlleva la nulidad del despido que invoque aquella causa», disponible en http://japariciotovar.blogspot.com/2020/02/la-derogacion-de-art-52-d-et-conlleva.html (consultado el 20 de abril).

${ }^{8}$ Poco antes de aprobarse el RDL se dictó por la Sala Social del Tribunal Superior de Justicia de Cataluña la importante Sentencia de 17 de febrero (Rec. 5532/2019). La sentencia considera inaplicable el art. 52.d) LET al supuesto litigioso en juego, por oponerse y ser contrario a diversos preceptos de normas internacionales, en aplicación del control de convencionalidad de las normas, siendo la consecuencia práctica de ello para la trabajadora despedida y para la empresa en la que prestaba sus servicios la declaración de improcedencia del despido y la condena a la readmisión o al abono de una algo más que sustancial indemnización, ya que la demandante tenía una antigüedad de casi cuarenta y tres años cuando se procedió a la extinción de su contrato «por faltas, aun justificadas de asistencia al trabajo», en concreto $\ll 160.876,80$ euros, de la que debe deducirse la indemnización que por cese del contrato percibió la actora, que asciende a 46.308,94 euros». El TSJ concluye, después de una muy cuidada y extensamente fundamentada argumentación jurídica, que el art. 52.d) LET no resulta de aplicación al caso, puesto que «de conformidad con el art. 31 de la Ley 25/2014, de 27 de noviembre, de Tratados y otros Acuerdos Internacionales, las normas convencionales deben prevalecer sobre el art. 52.d) LET en caso de conflicto». Para la Sala, al abordar dicho control de convencionalidad, y tras haber repasado la sentencia del TC, es decir el control de constitucionalidad que efectuó del art. 52.d) LET, las consideraciones que el TC efectúa sobre la adecuación del citado precepto legal al art. 6.1 del Convenio 158 de la OIT sobre la terminación de la relación de trabajo «constituyen un obiter dicta no vinculante, por caer fuera de su competencia la realización del control de convencionalidad de dicha norma, que corresponde a la jurisdicción ordinaria», y recuerda que partiendo de tal premisa, «en el control de adecuación de la ley interna a los Tratados y Convenios ratificados por España, hay que tener en cuenta que la jerarquía normativa superior del Tratado o convenio internacional sobre la ley se reconoce por la Convención de Viena de 23/05/69».
} 
mía Social de justificar debidamente la razón de la derogación del art. 52.d) LET, que desde luego sí lo hace y además exhaustivamente, sino también en el deseo de ir marcando las reglas del juego de aquello que ha de ser en el próximo futuro un cambio cuantitativa y cualitativamente muy importante de la normativa laboral vigente, tanto en materia de derechos individuales como colectivos (normativa sobre subcontratación, regulación de los efectos del despido, concurrencia de convenios, ultra-actividad, etc.), y no solo en el ámbito laboral, sino también en el penal (art. 315 del Código Penal, para despenalizar el ejercicio del derecho de huelga) y administrativo (reforma de la Ley sobre infracciones y sanciones en el orden social para modificar la tipificación de algunas actuaciones contrarias a derecho y aumentar por ello la cuantía de las sanciones a imponer). Está por ver, ciertamente, como impactará la grave crisis sanitaria provocada por la pandemia del Covid-19, con sus durísimas consecuencias económicas y sociales, en esos deseos y qué dificultades van a tener para poder convertirse en realidad.

El preámbulo tiene un claro contenido doctrinal, muy propio de un artículo académico que podría perfectamente publicarse en una revista especializada. Tiene también una clara impronta de género en el lenguaje utilizado, ya que, con independencia de la utilización del términos «trabajadores» cuando se hace referencia literal al texto del art. 52 LET, las restantes menciones relativas a quienes pueden verse afectados y afectadas por ese precepto se refieren a «la persona trabajadora», además de efectuar una expresa consideración sobre el impacto de esta medida negativamente sobre las mujeres trabajadoras por ser ellas quienes dedican más tiempo a los cuidados familiares, en una línea ya marcada por el voto particular de la magistrada María Luisa Balaguer a la STC que he examinado con anterioridad.

Y sobre el contenido concreto del preámbulo ¿qué hay que decir?

Hagamos un seguimiento ordenado del mismo. En primer lugar, el recordatorio de que en el marco normativo vigente, y tras las modificaciones operadas desde su redacción originaria en 1980, el supuesto factico que posibilita la extinción del contrato por causas objetivas, más coloquialmente denominado «despido por absentismo», queda reducido «a las faltas de asistencia injustificadas y a las bajas por contingencias comunes de duración inferior a veinte días», y a esta situación se llega, explica el preámbulo, tras todas las modificaciones operadas, de la que hay que destacar a mi parecer, y así también lo hace el RDL, la operada por la reforma de 2012 al eliminar el requisito de un porcentaje determinado de absentis- 
mo laboral en la empresa para poder proceder a la extinción del contrato de una persona trabajadora, algo que ya se subraya en el preámbulo, y se insistirá en varias ocasiones en esta tesis con apoyo en la jurisprudencia del TJUE, que lleva a que desde dicha reforma «el despido por faltas de asistencia del art. 52.d) del Estatuto de los Trabajadores se aplica en España cuando se alcanzan los porcentajes de faltas de asistencia establecidos, sin que el precepto requiera expresamente que se realice en cada caso juicio de adecuación y proporcionalidad», al mismo tiempo que se recuerda, a mayor abundamiento didáctico respecto a la posibilidad de extinguir el contrato de quien falta de forma injustificada al trabajo, que «el ordenamiento español ya dispone de mecanismos para asegurar la sanción para la persona que tiene faltas de asistencia injustificadas [art. 54.2.a) del Estatuto de los Trabajadores]».

El preámbulo da un trato prioritario y preferente a la jurisprudencia del TJUE, muy señaladamente a la Sentencia de 18 de enero de 2018, asunto C-270/16, caso Ruiz Conejero, de la que transcribe su fallo. Todo ello, en el marco de un análisis en el que quienes han redactado el preámbulo subraya con pleno acierto a mi parecer que cuando se debate sobre el «despido por absentismo» se confrontan intereses empresariales por una parte y de la parte trabajadora por otra, es decir «el legítimo interés de la empresa a contar con la fuerza de trabajo necesaria para el desarrollo del proyecto empresarial y a no tener que asumir los costes derivados de su falta y, de otro, el derecho de las personas trabajadoras a no ser penalizadas por circunstancias personales de las que no son responsables, como son las relacionadas con la enfermedad».

Una crítica que hubiera podido efectuarse a la justificación del RDL para derogar el art. 52.d) LET sería la de centrar de forma exclusiva su atención en la discriminación que la norma provoca en las personas con diversidad funcional, y es cierto que las sentencias del TJUE a las que se dedica atención en el preámbulo prestan una gran atención a la problemática de la discapacidad. Ahora bien, el precepto derogado no solo afecta a personas con diversidad funcional, sino que tal como ha quedado puesto de manifiesto en otras sentencias del TJUE, y posteriormente de juzgados y tribunales españoles, afecta a quienes se vean afectados y afectadas por enfermedades de larga duración y que dificulten su asistencia regular al trabajo, y no menos, ya lo he apuntado, a quienes por razones que pueden escapar de su voluntad debido al cuidado de otras personas de mayor o menor edad, que no son otras que las trabajadoras en quienes, datos estadísticos lo demuestran, asumen aún la mayor parte de la «economía de los cuidados». 
$\mathrm{Y}$ de estas situaciones también se hace eco diligente el preámbulo para subrayar que la afectación del art. 52.d) LET es, pues, más amplia, y que además (no nos olvidemos de que las relaciones de trabajo no son de equilibrio contractual, en cuanto que el poder de dirección, organización y sancionador corresponde a la parte empresarial) «genera en la persona trabajadora que ve extinguido su contrato una situación de gran vulnerabilidad profesional, personal y social», y añado por mi parte que también provoca una indudable tensión durante la vida de la relación laboral en las personas que, por bajas aun jutificadas, deben faltar al trabajo (si la razón de ser de la norma era sancionar a quien utilizaba las normas para «escabullirse» del trabajo, aunque no existiera realmente una causa que lo justificara, desde luego no ha tenido éxito, ya que los casos que han llegado a los juzgados y tribunales han puesto de manifiesto que realmente se trataba de bajas realmente justificadas por contingencias comunes.

Poca atención dedica el preámbulo a la STC núm. 118/2019, de 16 de octubre, objeto de análisis con anterioridad, salvo para recordar que dictaminó que el art. 52.d) no era contrario a la CE porque no vulneraba ni el derecho a la integridad física (art. 15), ni el derecho al trabajo (art. 31), ni el derecho a la protección de la salud (art. 43.1).

Sigue el preámbulo dedicando especial atención a la jurisprudencia del TJUE para subrayar aquellos contenidos que dan pie al cambio normativo ahora operado, en concreto la necesidad de que una decisión como es la extinción del contrato por faltas, aun justificadas, de asistencia al trabajo, esté condicionada en el caso de la discapacidad al análisis de adecuación y proporcionalidad (Sentencia de 18 de enero de 2018) y que, además, dicha medida debería ser la última a adoptar, ya que antes se debe proceder a realizar «ajustes razonables» en el puesto de trabajo (Sentencia de 11 de septiembre de 2019, asunto C-397/18, caso Nobel Plastiques, en la que el TJUE falló diciendo que la respuesta a las preguntas segunda a cuarta de la cuestión prejudicial era que los criterios de selección utilizados por la empresa podían significar la existencia de una discriminación indirecta por motivos de discapacidad, ex art. 2.2 de la Directiva 2000/78/CE, «a no ser que el empresario haya realizado previamente con respecto a ese trabajador ajustes razonables, en el sentido del art. 5 de la misma Directiva, a fin de garantizar la observancia del principio de igualdad de trato en relación con las personas con discapacidades, extremo que corresponde verificar al órgano jurisdiccional nacional»).

Adecuación y proporcionalidad que no se predican solo de la extinción derivada de la discapacidad, sino que debe aplicarse a cualquier otra situa- 
ción fáctica en que entren en juego, «se confronten», por utilizar la expresión utilizada en el preámbulo, los intereses empresariales y de la parte trabajadora. Es lo que lleva a la necesidad de derogar la norma, por cuanto ello no está recogido en el art. 52.d) que, señala con claridad y acierto el preámbulo, «se aplica con carácter automático cuando concurren los porcentajes de inasistencia que refiere», requiriendo por ello de su inmediata corrección normativa «a efectos de asegurar que se aplica adecuadamente en España la doctrina establecida por el TJUE».

Sigue a continuación una amplia exposición doctrinal sobre el despido objetivo y las diferencias existentes en la normativa española con respecto a otros ordenamientos en los que solo se efectúa una mención genérica al concepto de «despido por causa justa» y se remite a los juzgados y tribunales la apreciación de su concurrencia en cada caso enjuiciado, mientras que es distinta ciertamente la regulación en el marco normativo español, destacándose que «a diferencia de la mayoría de los ordenamientos europeos, el ordenamiento español establece, por tanto, un sistema de legitimación del despido objetivo en el que se establecen supuestos concretos y se especifican las circunstancias que deben concurrir para que el despido sea legal».

Como ya he indicado con anterioridad, la jurisprudencia del TJUE es objeto preferente de atención en el preámbulo para la justificación de la derogación del art. 52.d) LET. Además de las sentencias ya citadas, son también objeto de mención, con sintética explicación de su contenido para abundar en la tesis de aquella justificación, las de 11 de julio de 2006, asunto C-13/05, caso Chacón Navas; 11 de abril de 2013, asunto C-335/11, caso H. K. Danmark, y 1 de diciembre de 2016, asunto C-395/15, caso Daouidi), todas ellas punto de referencia para concluir que «la legitimación de cualquier despido que pueda recaer con mayor frecuencia en personas con discapacidad o con enfermedades de larga duración requiere de garantías más intensas de las que actualmente configura el actual art. 52.d) del Estatuto de los Trabajadores porque, tal y como advierte el Tribunal de Justicia de la Unión Europea, entra en juego el derecho a la no discriminación por razón de la discapacidad establecido en la Directiva 2000/78/CE del Consejo, de 27 de noviembre de 2000».

Por último, y voy concluyendo mi artículo, no desconocen quienes han redactado el texto que puede efectuarse la crítica de que se trata de un precepto datado de muchos años antes, y no solo, añado por mi parte, desde la reforma laboral de 2012, que es donde el RDL sitúa el centro del debate, sin duda por haber suprimido el requisito del porcentaje de bajas aun justificadas en el conjunto de la empresa, sino también desde etapas 
históricas anteriores y en donde gobernó durante muchos años el PSOE en solitario.

Salvan dichas posibles críticas con un buen y acertado argumento a mi parecer, cual es que la valoración de la extraordinaria y urgente necesidad de esta medida «es independiente de que tenga su origen en la previa inactividad del Gobierno», por cuanto el dato relevante «no es tanto la causa de las circunstancias que justifican la presente legislación de urgencia, cuanto el hecho de que tales circunstancias efectivamente concurren», con cita de la STC 11/2002, de 17 de enero, FJ 6», y reforzando su argumentación en el terreno temporal con la necesidad de cumplir con la jurisprudencia del TJUE plasmada en la Sentencia de 18 de enero de 2018. 